\section{Revista Brasileira de Administração Científica}

Brazilian Journal of Scientific Administration

Mai a Ago $2018-$ v.9 - n.2
RBADM

ISSN: 2179-684X

\title{
Qualidade do serviço prestado aos clientes da MGS: um estudo de caso com aplicação do SERVPERF
}

O setor de serviços recebe cada vez mais destaque na economia global, com participação nos produtos internos brutos acima da produção de bens em grandes países industrializados, como EUA e Reino Unido. Os serviços relacionados à manutenção das instalações, em especial, representam sempre um grande dispêndio de recursos para as organizações, já que são atividades de natureza indispensáveis para o desenvolvimento de qualquer organização. Nesse segmento, enquadrase a MGS, empresa pública do Estado de Minas Gerais, a qual a medição da qualidade dos serviços prestados aos clientes através do instrumento SERVPERF é o objetivo desse artigo. Aferir a qualidade de serviços é um grande desafio para as empresas, certamente mais difícil do que realizar a mesma aferição na produção de bens. Diante dos resultados, foi possível verificar que os serviços da MGS apresentam um nível de qualidade aceitável sendo possível inferir que, se não há satisfação plena, os clientes também não estão insatisfeitos com a qualidade dos serviços. Além disso, destaca-se que a confiabilidade do questionário aplicado foi atestada, considerando os resultados alcançados pelo alfa de Cronbach. A medição e acompanhamento da qualidade são passos fundamentais para a busca de melhoria contínua, e consequentemente o alcance da satisfação por parte dos clientes e devem ser tomados como desafios por qualquer organização que busque o sucesso.

Palavras-chave: Qualidade; Setor de serviços; SERVPERF.

\section{Quality of service provided to MGS customers: a case study with SERVPERF application}

\begin{abstract}
The services sector is increasingly prominent in the global economy, with a share of gross domestic products above the production of goods in large industrialized countries such as the United States and the United Kingdom. The services related to the maintenance of the facilities, in particular, always represent a great expense of resources for the organizations, since they are activities of nature indispensable for the development of any organization. In this segment, MGS, a public company of the State of Minas Gerais, is a company that measures the quality of services provided to customers through the SERVPERF instrument. Giving quality of services is a great challenge for companies, certainly more difficult than performing the same measurement in the production of goods. In view of the results, it was possible to verify that MGS services have an acceptable level of quality and it is possible to infer that, if there is not full satisfaction, clients are not dissatisfied with the quality of services. In addition, it is noted that the reliability of the questionnaire applied was attested, considering the results achieved by Cronbach's alpha. Quality measurement and monitoring are key steps in the pursuit of continuous improvement, and therefore customer satisfaction, and must be taken as challenges by any organization seeking success.
\end{abstract}

Keywords: Quality; Service sector; SERVPERF.

Topic: Marketing e Estratégias Mercadológicas

Reviewed anonymously in the process of blind peer
Received: 05/05/2018

Approved: 12/07/2018
Washington Gonçalo Rodrigues Veloso (iD

Centro Federal de Educação Tecnológica de Minas Gerais, Brasil http://lattes.cnpq.br/9845815477992745

http://orcid.org/0000-0002-0317-5469

washingtonveloso@gmail.com

Paulo Fernandes Sanches Junior (id)

Centro Federal de Educação Tecnológica de Minas Gerais, Brasil

http://lattes.cnpq.br/3148405797604378

http://orcid.org/0000-0002-1786-867X

sanches@cefetmg.br

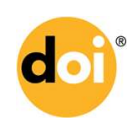

DOI: 10.6008/CBPC2179-684X.2018.002.0002
Referencing this:

VELOSO, W. G. R.; SANCHES JUNIOR, P. F.. Qualidade do serviço prestado aos clientes da MGS: um estudo de caso com aplicação do SERVPERF. Revista Brasileira de Administração Científica, v.9, n.2, p.13-25, 2018. DOI: http://doi.org/10.6008/CBPC2179$\underline{684 X .2018 .002 .0002}$ 


\section{INTRODUÇÃO}

Cada vez mais, o setor de serviços ganha importância na economia global. Slack (2003, citado por MIGUEL et al., 2004), revela que o setor de serviços compõe mais de 60\% do PIB do Reino Unido, e mais de 50\% do PIB dos Estados Unidos e da União Europeia. No Brasil, há uma dinâmica semelhante: dados do IBGE demonstram que 58\% das pessoas empregadas estão alocadas nos setores de serviços (IBGE, 2016). Em Minas Gerais, os serviços representaram, em média, $61,8 \%$ do valor adicionado bruto ao PIB mineiro entre 2010 e 2013, sendo que em 2013, especificamente, esse valor ultrapassou dois terços do total, demonstrando a tendência de crescimento desse setor (FJP, 2015).

Em outra análise, nota-se que os gastos relacionados às instalações, ou custos de ocupação, só são menores que os gastos com pessoal para as organizações, e que esses gastos são geralmente subestimados pelos gestores. Estratificando essa análise, os gastos com limpeza e conservação predial podem representar entre $20 \%$ e $40 \%$ do orçamento operacional (CAMPBELL, 2011; STOY et al., 2008; MADRISTCH, 2009, citado por SANTOS, 2014). Nesse grupo de serviços, que representa um volumoso dispêndio de recursos para as organizações, está o principal ramo de atividade da MGS.

A MGS - Minas Gerais Administração e Serviços S.A. é uma empresa pública do Estado de Minas Gerais, fundada em 1954, que pode atuar na prestação de serviços para os órgãos e entidades da Administração Pública do Brasil. A MGS é uma empresa pública não dependente do orçamento, tendo que se manter com as receitas da prestação de seus serviços. Tal situação exige que a companhia procure se manter no mercado utilizando de boas práticas de gestão empresarial, se preocupando com a qualidade das receitas e controle de custos e despesas.

Dados do Portal da Transparência do Estado de Minas Gerais demonstram que o valor liquidado em favor da MGS alcançou no exercício de 2015 a marca de $\mathrm{R} \$ 629.833 .382,81$. Em outra pesquisa nesse portal, filtrando os itens de despesas 'locação de serviços de apoio administrativo, 'locação de serviços de apoio administrativo realizados pela MGS', 'locação de serviços de conservação e limpeza', 'locação de serviços de conservação e limpeza realizados pela MGS', 'outros serviços pessoa jurídica', 'serviços de atendimento ao cidadão' e 'serviços de conservação e limpeza', a MGS sozinha representou 52,15\%, dos mais de um bilhão de reais liquidados para esses serviços. 0 gráfico 1 representa essa situação.

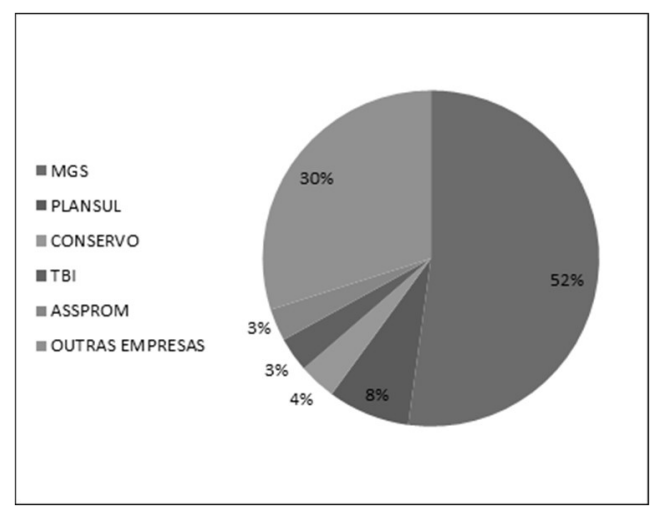

Gráfico 1: Participação nos valores liquidados pelo Estado de Minas Gerais para prestação de serviços, por favorecido, no exercício de 2015. 
Antes dessa pesquisa, aplicada em 2016, não há histórico de pesquisas de satisfação ou qualidade de serviços junto aos clientes da MGS, o que prejudica as análises e comparações do presente e passado. A implantação de instrumentos voltados para medir a qualidade dos serviços prestados aos clientes e, também, compreender de maneira sistemática suas necessidades é um desafio para a companhia. Já está em preparação uma segunda rodada de aplicação da pesquisa, utilizando a proposta desse trabalho como base.

Muito se fala sobre o desafio de avaliar serviços acima de avaliar bens. Isso se dá pelas características exclusivas dos serviços que os diferenciam. Slack et al. (2002) destaca a intangibilidade, a impossibilidade de estocar, a impossibilidade de transportar, a obrigatoriedade de consumo simultâneo e o julgamento pelo cliente em todo o processo, como as principais caraterísticas de distinção.

Nesse estudo, o instrumento SERVPERF foi a ferramenta escolhida para medir a qualidade dos serviços prestados aos clientes da MGS. O instrumento SERVPERF é uma metodologia proposta por Cronin et al. (1992) que visa mensurar a qualidade de serviços através da medição da performance. Essa mensuração é feita através de um questionário, aplicado junto aos clientes, cujas perguntas são fundadas nas cinco dimensões da qualidade, que são: Confiança, Receptividade, Segurança, Empatia e Tangibilidade.

\section{REVISÃO TEÓRICA}

\section{Qualidade em Serviços}

Slack et al. (2002), definem que "qualidade é a consistente conformidade com as expectativas dos consumidores.". Os mesmos autores estabelecem seis passos para alcançar a qualidade em produtos ou serviços, quais sejam, respectivamente: Definir as características de qualidade do produto ou serviço; Definir como medir cada característica de qualidade; Estabelecer padrões de qualidade para cada característica de qualidade; Controlar a qualidade em relação a esses padrões; Encontrar e corrigir causas de má qualidade; e Continuar a fazer melhoramentos.

Os serviços apresentam características que os diferem drasticamente dos bens, eles geralmente são: intangíveis (ainda que seja possível ver ou sentir seus resultados, não é possível tocá-los), não estocáveis, intransportáveis, de consumo simultâneo, de alto nível de contato com o consumidor e qualidade julgada por todo o processo (SLACK et al., 2002). Parasuramam et al. (1985) resume as principais diferenças em intangibilidade, heterogeneidade e inseparabilidade. Todas essas caraterísticas fazem da atividade de avaliar a qualidade em serviços uma tarefa mais árdua do que avaliar bens.

Considerando essa complexidade, vários autores já estudaram o tema em busca de soluções viáveis. Miguel et al. (2004) apresenta uma série de modelos utilizados para a mensuração de qualidade em serviços, representados no quadro 1; todavia, conclui que não há consenso na literatura sobre qual modelo é mais adequado, além de levantarem questões ainda não respondidas, como influência do preço na satisfação, causalidade entre satisfação de clientes e qualidade de serviços e a utilização de modelos para medição de serviços internos. Dos modelos apresentados, o SERVQUAL (PARASURAMAM et al., 1985, 1988, 1991) e o SERVPERF (CRONIN et al., 1992, 1994), que foi formulado a partir de uma crítica ao SERVQUAL, serão destacados nesse trabalho. $O$ instrumento SERVPERF será utilizado para aplicação da pesquisa de satisfação. 
Quadro 1: Resumo dos modelos de qualidade da literatura.

\begin{tabular}{|c|c|c|c|}
\hline Autor (es) & Características Principais & Conclusões Principais & Área de Aplicação \\
\hline $\begin{array}{l}\text { Grönroos } \\
\text { (1984) }\end{array}$ & $\begin{array}{l}\text { Qualidade = } \mathrm{f} \text { (expectativa, } \\
\text { desempenho e imagem) }\end{array}$ & $\begin{array}{l}\text { - Interação comprador /vendedor é mais } \\
\text { importante que atividades de marketing. } \\
\text { - Contato comprador/vendedor tem mais influência } \\
\text { na formação da imagem que atividades de } \\
\text { marketing. }\end{array}$ & $\begin{array}{l}\text { Diversos tipos de } \\
\text { Serviços }\end{array}$ \\
\hline $\begin{array}{l}\text { Parasuraman } \\
\text { et al. } \\
(1985,1988)\end{array}$ & $\begin{array}{l}22 \text { itens distribuídos em cinco } \\
\text { dimensões da qualidade }\end{array}$ & $\begin{array}{l}\text { - A qualidade de serviços pode ser quantificada. } \\
\text { - Determina cinco dimensões genéricas para todos } \\
\text { os tipos de serviços. } \\
\text { - A qualidade dos serviços é diferença entre } \\
\text { expectativa e desempenho ao longo das dimensões. }\end{array}$ & $\begin{array}{l}\text { Diversos tipos de } \\
\text { Serviços }\end{array}$ \\
\hline $\begin{array}{l}\text { Brown e } \\
\text { Swartz } \\
(1989)\end{array}$ & $\begin{array}{l}\text { Utiliza as } 10 \text { dimensões } \\
\text { desenvolvidas por } \\
\text { Parasuraman et al. (1985) }\end{array}$ & $\begin{array}{l}\text { - A qualidade dos serviços é a diferença entre } \\
\text { desempenho e expectativa ao longo das dimensões. }\end{array}$ & $\begin{array}{l}\text { Atendimento em } \\
\text { consultórios da área } \\
\text { médica }\end{array}$ \\
\hline $\begin{array}{l}\text { Bolton e Drew } \\
\text { (1991) }\end{array}$ & $\begin{array}{l}\text { - Utiliza quatro dimensões } \\
\text { desenvolvidas por } \\
\text { Parasuraman et al. (1988) } \\
\text { - Introduz o conceito do valor } \\
\text { na avaliação da qualidade do } \\
\text { cliente }\end{array}$ & $\begin{array}{l}\text { - Concluem que as características dos clientes } \\
\text { influenciam as avaliações de qualidade e valor pelo } \\
\text { cliente. } \\
\text { - A não confirmação das expectativas está mais } \\
\text { fortemente correlacionada com a qualidade dos } \\
\text { serviços. }\end{array}$ & Serviços de telefonia \\
\hline $\begin{array}{l}\text { Cronin e } \\
\text { Taylor } \\
(1992)\end{array}$ & $\begin{array}{l}\text { Utiliza as cinco dimensões } \\
\text { gerais desenvolvidas por } \\
\text { Parasuraman et al. (1988) }\end{array}$ & $\begin{array}{l}\text { - Avaliação de qualidade de serviços é melhor } \\
\text { representada pela desempenho ao longo das } \\
\text { dimensões }\end{array}$ & $\begin{array}{l}\text { Diversos tipos de } \\
\text { Serviços }\end{array}$ \\
\hline Teas (1993) & $\begin{array}{l}\text { Utiliza as cinco dimensões } \\
\text { gerais desenvolvidas por } \\
\text { Parasuraman et al. (1988) }\end{array}$ & $\begin{array}{l}\text { - O modelo do desempenho ideal tem maior } \\
\text { correlação com as preferências de compra, } \\
\text { intenções de recompra e satisfação com os serviços }\end{array}$ & Lojas de varejo \\
\hline
\end{tabular}

Fonte: Miguel et al. (2004).

\section{SERVQUAL}

Parasuramam et al. (1985) afirmou em seu trabalho que a medição da satisfação do cliente é alcançada por uma função da diferença entre o serviço originalmente esperado e o que foi recebido. Essa afirmação possibilitou Parasuramam et al. (1985) a criar um modelo de qualidade de serviços, após uma série de entrevistas com executivos, aonde foi determinado os tipos de diferenças (gaps) principais na avaliação de serviços.

O Gap 1 trata da diferença entre o serviço esperado pelo consumidor e as percepções da gerência quanto a essas expectativas; um exemplo para essa situação é de cujos consumidores demandem privacidade e confidencialidade na execução dos serviços, todavia, esses pontos raramente foram mencionados pelos executivos. O Gap 2 trata da diferença entre as percepções da gerência quanto às expectativas do consumidor e as especificações da qualidade dos serviços, nas entrevistas com os executivos ficou demonstrado que há baixa qualidade de serviços, mesmo em empresas cujos procedimentos são bem detalhados (PARASURAMAM et al., 1985).

Parasuramam et al. (1985) descreve o Gap 3 como a diferença entre as especificações e o serviço entregue, incluindo os diversos contatos com o consumidor. O Gap 4 trata da diferença entre o serviço entregue e o serviço prometido pela comunicação da empresa com seus consumidores. Por fim, Parasuramam et al. (1985) propõe a existência do Gap 5 que é a função dos demais gaps, em suma, a diferença entre o serviço originalmente esperado e o que foi recebido. $O$ trabalho de Parasuramam et al. (1985) também generalizou os critérios utilizados pelos consumidores em geral para medir a qualidade em serviços. Esses critérios foram agrupados em dez determinantes, demonstradas no quadro 2. 
Quadro 2: Determinantes da qualidade.

\begin{tabular}{|c|c|}
\hline Determinante & Definição \\
\hline Confiança & $\begin{array}{l}\text { Envolve a consistência do desempenho e da confiança. } \\
\text { Significa que a empresa faz o serviço certo da primeira vez. } \\
\text { Também significa que a empresa honra seus compromissos. Especificamente envolve: } \\
\text { - precisão no faturamento; } \\
\text { - manutenção correta de registros; } \\
\text { - entrega do serviço no tempo acordado. }\end{array}$ \\
\hline Receptividade & $\begin{array}{l}\text { Refere-se à boa vontade ou prontidão dos empregados em prestar o serviço. Envolve a pontualidade } \\
\text { no serviço: } \\
\text { - enviar imediatamente um recibo; } \\
\text { - retornar rapidamente a ligação de um consumidor; } \\
\text { - prestar pronto atendimento (abrir espaço na agenda rapidamente) }\end{array}$ \\
\hline Competência & $\begin{array}{l}\text { Significa possuir as habilidades e conhecimento necessários para realizar o serviço. Envolve: } \\
\text { - conhecimento e habilidade da equipe de atendimento; } \\
\text { - conhecimento e habilidade da equipe de apoio operacional; } \\
\text { - capacidade de pesquisa da organização. }\end{array}$ \\
\hline Acesso & $\begin{array}{l}\text { Envolve proximidade e facilidade de contato. Significa: } \\
\text { - o serviço é facilmente acessível por telefone (as linhas não ficam ocupadas); } \\
\text { - o tempo de espera para receber o serviço não é excessivo; } \\
\text { - o horário de funcionamento é conveniente; } \\
\text { - o local de prestação dos serviços é conveniente. }\end{array}$ \\
\hline Cortesia & $\begin{array}{l}\text { Envolve educação, respeito, consideração e contato pessoal amigável. Inclui: } \\
\text { - consideração com a propriedade do cliente (por exemplo, não usar sapatos sujos de lama no } \\
\text { carpete do cliente); } \\
\quad \text { - aparência limpa e arrumada do pessoal que tem contato com o público. }\end{array}$ \\
\hline Comunicação & $\begin{array}{l}\text { Significa manter os clientes informados em uma linguagem possa ser compreendida por eles. Pode } \\
\text { significar que a empresa tenha de ajustar sua linguagem a diferentes tipos de consumidores - } \\
\text { aumentando o nível de sofisticação com consumidores bem instruídos e falando simples e claramente } \\
\text { com consumidores sem experiência. Envolve: } \\
\quad \text { - explicar o serviço em si; } \\
\quad \text { - explicar quanto custará o serviço; } \\
\quad \text { - explicar os trade-offs entre o serviço e o preço; } \\
\text { - assegurar ao cliente qual problema será resolvido. }\end{array}$ \\
\hline Credibilidade & $\begin{array}{l}\text { Inclui confiabilidade, confiança e honestidade. Envolve tomar como seus os interesses do cliente. } \\
\text { Contribui para a credibilidade: } \\
\text { - o nome da empresa; } \\
\text { - a reputação da empresa; } \\
\text { - caraterísticas pessoais da equipe de atendimento; } \\
\text { - e a integração com o cliente durante a venda. }\end{array}$ \\
\hline Segurança & $\begin{array}{l}\text { É a ausência de perigo, risco ou dúvida. Envolve: } \\
\text { - segurança física; } \\
\text { - segurança financeira; } \\
\text { - confidencialidade. }\end{array}$ \\
\hline $\begin{array}{l}\text { Compreensão e } \\
\text { Conhecimento do } \\
\text { Cliente }\end{array}$ & $\begin{array}{l}\text { Envolve se esforçar para entender as necessidades do cliente. Inclui: } \\
\text { - aprender sobre requisitos específicos do cliente; } \\
\text { - prover atenção individualizada; } \\
\text { - reconhecer clientes fiéis. }\end{array}$ \\
\hline Tangibilidade & $\begin{array}{l}\text { Inclui o espaço físico da prestação de serviços: } \\
\text { - dependências físicas; } \\
\text { - aparência do pessoal; } \\
\text { - ferramentas e equipamentos utilizados na prestação dos serviços; } \\
\text { - representações físicas do serviço; } \\
\text { - outros clientes presentes nas dependências físicas. }\end{array}$ \\
\hline
\end{tabular}

Fonte: Parasuramam et al. (1985).

Evoluindo em seu trabalho, Parasuramam et al. (1988) condessou as dez determinantes em cinco dimensões da qualidade. Elas são: Confiança (capacidade de prestar o serviço com precisão); Receptividade (auxílio ao cliente e pronto atendimento); Segurança (habilidade de transmitir confiança ao cliente); Empatia (cuidado e atenção com cliente); e Tangibilidade (dependências físicas, aparência do pessoal, ferramentas, equipamentos e material de comunicação). A partir das cinco dimensões e do modelo de gaps, os autores desenvolveram o instrumento SERVQUAL. 
O instrumento SERVQUAL é um questionário, cujo modelo tradicional conta com vinte e dois itens distribuídos pelas cinco dimensões da qualidade, utilizando de uma escala Likert de sete pontos. Cada item deveria conter duas declarações, uma de maneira genérica para medição do serviço esperado e outra para a empresa específica, em busca de medir o serviço efetivamente prestado, ou seja, ao todo os respondentes devem responder quarenta e quatro declarações. (PARASURAMAM et al., 1985).

Em um refinamento do instrumento SERVQUAL, Parasuramam et al. (1991) propôs a exclusão de todas as declarações negativas, que eram aproximadamente metade dos itens, por declarações afirmativas. Eles também substituíram as expressões 'deveriam' por outras que não aumentassem a expectativa dos consumidores.

\section{SERVPERF}

Cronin et al. (1992) desenvolveu o modelo SERVPERF a partir de críticas ao instrumento SERVQUAL. Cronin et al. (1992) entende que o SERVQUAL, ao propor a comparação entre o serviço esperado e o serviço executado, conseguiria mensurar a percepção de qualidade pelo consumidor, mas não a qualidade em si. 0 modelo SERVPERF utiliza das mesmas cinco dimensões da qualidade e dos vinte e dois itens baseados nessas dimensões, propostos por Parasuramam et al. (1988), conforme demonstrado na figura 1; todavia, enfatizaram que a medição da qualidade deveria ocorrer somente sobre o serviço prestado, sem levar em conta as expectativas prévias.

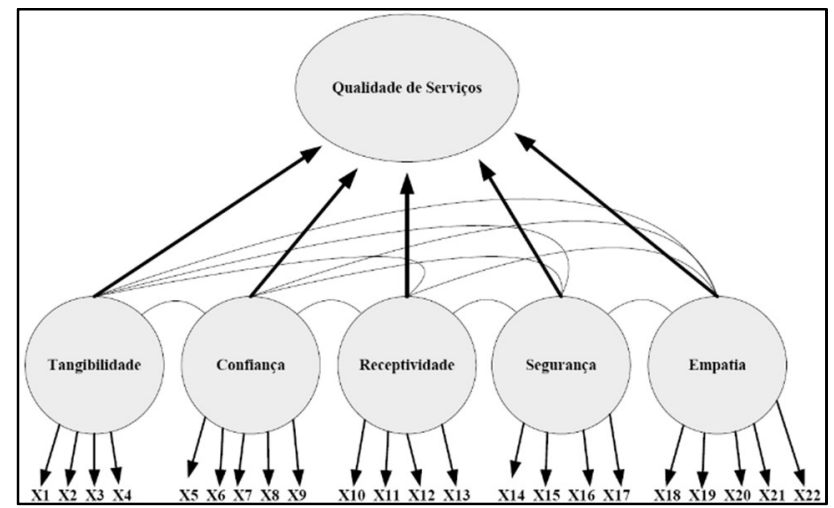

Figura 1: Modelo de qualidade de serviços. Fonte: Cronin et al. (1994); Parasuramam et al. (1988).

A pesquisa original de Cronin et al. (1992) buscava, em primeiro lugar, provar que o instrumento SERVQUAL era inadequado para mensuração da qualidade de serviços, ao afirmar que a medição dos gaps era superada pela simples medição da performance. Cronin et al. (1992) afirma que há evidências que comprovam que a satisfação antecede a qualidade de serviços em si, logo, o modelo expectativa menos desempenho falharia na medição da qualidade, considerando o alto nível de subjetividade em função da percepção do cliente. Em segundo lugar o estudo buscava examinar a relação entre qualidade de serviços, satisfação do consumidor e intenção de compra por ser, até então, um tema pouco explorado pela academia e mercado.

O SERVPERF utiliza de um questionário de estrutura semelhante ao do SERVQUAL, com declarações referentes a vinte e dois itens, distribuídos pelas cinco dimensões da qualidade (figura 1), já que os autores 
acreditavam que a construção teórica do SERVQUAL foi bem conceituada. Essas declarações deveriam ser respondidas pelos clientes dentro de uma escala Likert de sete pontos, variando de (1) 'discordo totalmente' a (7) 'concordo totalmente'. As perguntas originais foram transcritas no quadro 3. É importante salientar que nesse modelo só há declarações que visam mensurar o serviço prestado. Além disso, foram incluídas outras três declarações que visam medir: a intenção de retorno do cliente, a qualidade geral do serviço e a satisfação do cliente (CRONIN et al., 1992).

Quadro 3: Declarações utilizadas no instrumento SERVPERF.

\begin{tabular}{|l|l|c|}
\hline Item & \multicolumn{1}{|c|}{ Declaração } & Dimensão \\
\hline 1 & Os equipamentos da empresa XYZ são atualizados e modernos. & Tangibilidade \\
\hline 2 & As instalações físicas da empresa XYZ são atrativas. & \\
\hline 3 & Os empregados da empresa XYZ são limpos e bem vestidos. & Confiança \\
\hline 4 & As instalações físicas da empresa XYZ são condizentes com o serviço prestado. & \\
\hline 5 & As promessas da empresa XYZ são cumpridas. & Receptividade \\
\hline 6 & Quando você tem algum problema, a empresa XYZ é solidária e o tranquiliza. & \\
\hline 7 & A empresa XYZ é confiável. & Segurança \\
\hline 8 & A empresa XYZ entrega os serviços no prazo prometido. & \\
\hline 9 & A empresa XYZ mantém os registros históricos de maneira adequada. & \\
\hline 10 & A empresa XYZ não informa aos clientes quando os serviços serão prestados. & \multirow{2}{*}{ Empatia } \\
\hline 11 & Os empregados da empresa XYZ não prestam um pronto atendimento. & \\
\hline 12 & Os empregados da empresa XYZ não ficam sempre à disposição para auxiliar os clientes. & \\
\hline 13 & Os empregados da empresa XYZ são muito ocupados para responder aos clientes prontamente. & \\
\hline 14 & Você pode confiar nos empregados da empresa XYZ. & \\
\hline 15 & Você se sente seguro ao negociar com os empregados da empresa XYZ. & \\
\hline 16 & Os empregados da empresa XYZ são educados. & \\
\hline 17 & Os empregados tem o suporte adequado da empresa XYZ para realizar o seu trabalho. & \\
\hline 18 & A empresa XYZ não te dá atenção individual. \\
\hline 19 & Os empregados da empresa XYZ não te dão atenção personalizada. & \\
\hline 20 & Os empregados da empresa XYZ não conhecem suas necessidades. & \\
\hline 21 & A empresa XYZ não coloca seus interesses como prioridade. & \\
\hline 22 & O horário de operação da empresa XYZ não é conveniente aos seus clientes. & \\
\hline
\end{tabular}
Fonte: Cronin et al. (1992).

Cronin et al. (1992) conclui, através de testes estatísticos, que o modelo SERVPERF é mais adequado do que o SERVQUAL para mensuração da qualidade em serviços, destacando que a ferramenta tem aplicação mais simples, por conter um questionário consideravelmente menor, enfrentando menos resistência dos respondentes. Além disso, outras pesquisas posteriores corroboram com a hipótese de melhor adequação do SERVPERF para medição de qualidade em serviços, em comparação com o SERVQUAL (MIGUEL et al., 2005; MAIA et al., 2007; SILVA et al., 2009). O quadro 4 traz a relação de algumas pesquisas que utilizaram do SERVPERF.

Quadro 4: Aplicação do SERVPERF na literatura.

\begin{tabular}{|l|l|l|}
\hline \multicolumn{1}{|c|}{ Autor (es) } & \multicolumn{1}{|c|}{ Título } & \multicolumn{1}{c|}{ Considerações dos autores } \\
\hline $\begin{array}{l}\text { Miguel, } \\
\text { Salomi e } \\
\text { Abackerli } \\
(2005)\end{array}$ & $\begin{array}{l}\text { SERVQUAL X SERVPERF: } \\
\text { comparação entre } \\
\text { instrumentos para avaliação } \\
\text { da qualidade de serviços } \\
\text { internos }\end{array}$ & $\begin{array}{l}\text { O trabalho conclui sobre a viabilidade de utilização do SERVPERF e SERVQUAL } \\
\text { para a medida da qualidade do serviço da empresa estudada, não havendo } \\
\text { restrições quanto aos estimadores de confiabilidade e validade, os quais são da } \\
\text { mesma ordem de grandeza quando aplicados para avaliação de qualidade de } \\
\text { serviços externos. Deve-se enfatizar a considerável vantagem de utilização da } \\
\text { escala SERVPERF que é a redução das questões, simplificando a } \\
\text { operacionalização da pesquisa e evitando a desmotivação do respondente. }\end{array}$ \\
\hline $\begin{array}{l}\text { Maia, } \\
\text { Salazar, e } \\
\text { Ramos } \\
\text { (2007) }\end{array}$ & $\begin{array}{l}\text { A adequação dos modelos } \\
\text { SERVQUAL e SERVPERF na } \\
\text { medição da qualidade de } \\
\text { serviço: o caso da RAR } \\
\text { Imobiliária }\end{array}$ & $\begin{array}{l}\text { A escala SERVPERF, com base nas percepções de performance do serviço } \\
\text { prestado, é adequada para medir as qualidade do serviço prestado pela RAR } \\
\text { Imobiliária. }\end{array}$ \\
\hline
\end{tabular}




\begin{tabular}{|l|l|l|}
\hline $\begin{array}{l}\text { Lee e Beeler } \\
\text { (2007) }\end{array}$ & $\begin{array}{l}\text { The relationships among } \\
\text { quality, satisfaction, and } \\
\text { future intention for first-time } \\
\text { and repeat visitors in a } \\
\text { festival setting }\end{array}$ & $\begin{array}{l}\text { O SERVPERF é um método melhor do que o SERVQUAL em termos de } \\
\text { confiabilidade e validade, e tem grande vantagem na coleta de dados, já que o } \\
\text { foco só em performance, evita gastar tempo medindo tanto expectativa quanto } \\
\text { performance. }\end{array}$ \\
\hline $\begin{array}{l}\text { Silva, } \\
\text { Medeiros e } \\
\text { Costa (2009) }\end{array}$ & $\begin{array}{l}\text { Qualidade dos serviços } \\
\text { turísticos no setor de } \\
\text { restaurantes: uma aplicação } \\
\text { do modelo SERVPERF }\end{array}$ & $\begin{array}{l}\text { O instrumento SERVPERF teve sua validade reforçada pela análise de } \\
\text { confiabilidade, que indicou que o instrumento é útil, consistente e capaz de } \\
\text { reproduzir o nível de qualidade de serviços. Um ponto negativo é a sua } \\
\text { extensão, que as vezes tornava cansativo o processo de resposta. }\end{array}$ \\
\hline
\end{tabular}

\section{METODOLOGIA}

Esse trabalho é uma pesquisa qualitativa de natureza descritiva, que para aprofundar no assunto, utilizou de um estudo de caso. De acordo com Maanen (1979) a pesquisa qualitativa é compreendida por um conjunto de técnicas interpretativas para descrição e decodificação, dando sentido aos fenômenos do mundo social. A pesquisa descritiva expõe as características de determinada população ou fenômeno, estabelece correlações entre variáveis e define sua natureza, ela não explica os fenômenos descritos, mas serve de base para isso (VERGARA, 2000). Gil (1999) define estudo de caso como um estudo de um ou poucos objetos, realizado de maneira mais profunda, permitindo o conhecimento amplo do tema.

O instrumento SERVPERF é uma ferramenta para medição de qualidade em serviços proposta por Cronin et al. (1992), que utiliza de um questionário de afirmações fechadas não dependentes. O questionário é "uma técnica estruturada para coleta de dados que consiste em uma série de perguntas, escritas ou orais, que um entrevistado deve responder" (MALHOTRA, 2006). O objetivo do questionário é conhecer "opiniões, crenças, sentimentos, interesses, expectativas, situações vivenciadas, etc." (GIL, 1999).

O questionário SERVPERF, utilizado nessa pesquisa, conforme preconizado na pesquisa de Cronin et al. (1992) conta com vinte e duas declarações distribuídas entre as cinco dimensões da qualidade. As declarações de x1 a x4 são vinculadas à dimensão 'tangibilidade', de x5 a x9 à dimensão 'confiança', de x10 a x13 à dimensão 'receptividade', de x14 a x17 à dimensão 'segurança', e por fim de x18 a x22 à dimensão 'empatia'.

Como é explicitado na revisão teórica, o questionário SERVPERF original utilizou como base o instrumento SERVQUAL proposto na pesquisa de Parasuramam et al. (1988). Nesse trabalho, os refinamentos do SERVQUAL propostos por Parasuramam et al. (1991) foram extrapolados para o questionário SERVPERF formulado, por isso não foram utilizadas declarações negativas, presentes em aproximadamente metade dos itens do SERVPERF original, logo, foram utilizadas somente declarações afirmativas.

Além dos vinte e dois itens relacionados às cinco dimensões da qualidade, o questionário contou com mais quatro declarações, que buscaram medir: a intenção do cliente em voltar a fazer negócios com a MGS; a qualidade geral do serviço; a satisfação do cliente; e o impacto da reestruturação dos processos na qualidade dos serviços. $\mathrm{O}$ início do questionário contou também com perguntas demográficas para análise atual e futura do perfil dos respondentes, as perguntas buscaram levantar: a esfera da administração pública a qual se vincula o cliente; o poder da administração pública ao qual se vincula o cliente; a caracterização do cliente dentro da administração pública; o tempo de contratação da MGS pelo cliente; e o tempo de gestão do respondente à frente do cliente. 
Os dados foram coletados através de questionário eletrônico, utilizando a ferramenta de formulários do Google, considerando a facilidade de acesso para os respondentes e para tabulação dos dados obtidos. $O$ número potencial de respondentes dessa pesquisa é relativamente baixo para atestar a validade do questionário através de análise fatorial. Conforme conceituado por Hair et al. (2005), para utilizar da análise fatorial é recomendável uma amostra igual ou maior a 100 e que o montante de observações seja no mínimo cinco vezes maior do que a quantidade de variáveis a serem analisadas. Todavia, conforme fora explicitado ao longo desse trabalho o questionário SERVPERF é amplamente utilizado e já validado nos meios acadêmicos, sendo assim, é possível afirmar que essa etapa não é prejudicial à pesquisa.

Por conseguinte, para análise dos resultados, os dados obtidos foram tabulados no Microsoft Excel, tratados com o IBM SPSS Statistics e examinados por meio da média aritmética das respostas. Foram observadas também as diferenças entre os grupos, levantadas através das perguntas demográficas do questionário. Além disso, foi utilizado do alfa de Cronbach, para analisar a confiabilidade sobre as dimensões da qualidade de serviços. Hair et al. (2005) conceitua o alfa de Cronbach como uma medida de confiabilidade estatística, que pode variar de 0 a 1, estabelecendo 0,60 e 0,70 como os limites inferiores de aceitabilidade.

\section{RESULTADOS E DISCUSSÃO}

O questionário de caráter anônimo, foi aplicado entre os dias 19/09/2016 e 19/10/2016, para os gestores dos sessenta e sete clientes da MGS. Desses quarenta e dois, ou $62,69 \%$ da população, responderam. A tabela 1 demonstra o valor médio das respostas obtidas nas 26 declarações do questionário SERVPERF aplicado. Todas as dimensões apresentaram resultados acima da opção 'não concordo, nem discordo', sendo possível inferir que, se não há satisfação plena, os clientes também não estão insatisfeitos com a qualidade dos serviços. O melhor resultado foi da dimensão 'segurança', com 4,77 e o pior do agrupamento das quatro declarações que buscavam medir amplas intenções dos clientes, aqui chamado de 'negócios'.

Analisando as vinte e seis declarações separadamente, a que visava medir a educação dos empregados foi a que obteve maior média, a única acima de 5 pontos, alcançando 5,21. As outras declarações melhores colocadas foram seguidas pela conveniência do horário de operação, com 4,98; confiança nos empregados, com 4,93; e confiança na empresa, com 4,90, destacando que as três melhores se colocam entre os quatro menores desvio padrão, representando maior homogeneidade nas respostas.

A declaração com pior resultado foi a que buscava medir o prazo de entrega, alcançando apenas 3,93. As declarações sobre pronto-atendimento; suporte da empresa aos empregados para realização do trabalho; e a priorização de interesses individuais, ficaram empatadas na segunda pior colocação, alcançando 4,11. Das vinte e seis declarações, uma ficou acima de 5 pontos; quinze entre 4,5 e 4,99; nove entre 4 e 4,49; e uma abaixo de 4. 
Tabela 1: Valor médio dos indicadores de qualidade.

\begin{tabular}{|c|c|c|c|c|c|}
\hline Dimensão & Declaração & Média ${ }^{1}$ & \begin{tabular}{|l|} 
Desvio \\
Padrão
\end{tabular} & $\begin{array}{l}\text { Média da } \\
\text { Dimensão }\end{array}$ & $\begin{array}{l}\text { Desvio Padrão da } \\
\text { Dimensão }\end{array}$ \\
\hline Tangibilidade & $\begin{array}{l}\text { [Os insumos entregues pela MGS são adequados } \\
\text { aos serviços prestados.] }\end{array}$ & 4,6429 & 1,10036 & \multirow{4}{*}{4,5952381} & \multirow{4}{*}{1,18729054} \\
\hline Tangibilidade & $\begin{array}{l}\text { [A estrutura tecnológica da MGS (portal, área do } \\
\text { cliente) atende suas necessidades.] }\end{array}$ & 4,5714 & 1,25218 & & \\
\hline Tangibilidade & $\begin{array}{l}\text { [Os empregados da MGS utilizam vestimentas } \\
\text { adequadas aos serviços prestados.] }\end{array}$ & 4,5952 & 1,48257 & & \\
\hline Tangibilidade & $\begin{array}{l}\text { [As instalações físicas da administração central da } \\
\text { MGS são suficientes para suportar o serviço } \\
\text { prestado.] }\end{array}$ & 4,5714 & 1,01556 & & \\
\hline Confiança & [A MGS cumpre suas obrigações contratuais.] & 4,3810 & 1,43054 & \multirow{5}{*}{4,5} & \multirow{5}{*}{1,46720893} \\
\hline Confiança & $\begin{array}{l}\text { [Quando você tem algum problema a MGS } \\
\text { demonstra interesse em resolvê-lo.] }\end{array}$ & 4,7619 & 1,49486 & & \\
\hline Confiança & [A MGS é confiável.] & 4,9048 & 1,41092 & & \\
\hline Confiança & [A MGS entrega os serviços no prazo prometido.] & 3,9286 & 1,59867 & & \\
\hline Confiança & $\begin{array}{l}\text { [A MGS mantém os registros históricos de maneira } \\
\text { adequada.] }\end{array}$ & 4,5238 & 1,19426 & & \\
\hline Receptividade & $\begin{array}{l}\text { [Os empregados da administração da MGS } \\
\text { entregam as informações da forma correta.] }\end{array}$ & 4,6905 & 1,35229 & \multirow{4}{*}{4,44642857} & \multirow{4}{*}{1,31298377} \\
\hline Receptividade & $\begin{array}{l}\text { [Os empregados da administração da MGS } \\
\text { prestam um pronto atendimento.] }\end{array}$ & 4,4524 & 1,34713 & & \\
\hline Receptividade & $\begin{array}{l}\text { [Os empregados da administração da MGS ficam } \\
\text { sempre à disposição para auxiliar os clientes.] }\end{array}$ & 4,5238 & 1,32955 & & \\
\hline Receptividade & $\begin{array}{l}\text { [Os empregados da administração da MGS nunca } \\
\text { estão muito ocupados para responder aos clientes } \\
\text { prontamente.] }\end{array}$ & 4,1190 & 1,32890 & & \\
\hline Segurança & [você pode confiar nos empregados da MGS.] & 4,9286 & ,97262 & \multirow{4}{*}{4,77380952} & \multirow{4}{*}{1,14515811} \\
\hline Segurança & $\begin{array}{l}\text { [Você se sente seguro ao negociar com os } \\
\text { empregados da MGS.] }\end{array}$ & 4,8333 & 1,10247 & & \\
\hline Segurança & [Os empregados da MGS são educados.] & 5,2143 & ,78198 & & \\
\hline Segurança & $\begin{array}{l}\text { [Os empregados tem o suporte adequado da MGS } \\
\text { para realizar o seu trabalho.] }\end{array}$ & 4,1190 & 1,46841 & & \\
\hline Empatia & [A MGS te dá atenção individual.] & 4,5238 & 1,15269 & \multirow{5}{*}{4,53333333} & \multirow{5}{*}{1,13521519} \\
\hline Empatia & $\begin{array}{l}\text { [Os empregados da administração da MGS te dão } \\
\text { atenção personalizada.] }\end{array}$ & 4,4762 & 1,13133 & & \\
\hline Empatia & $\begin{array}{l}\text { [Os empregados da administração da MGS } \\
\text { conhecem suas necessidades.] }\end{array}$ & 4,5714 & 1,12927 & & \\
\hline Empatia & [A MGS coloca seus interesses como prioridade.] & 4,1190 & 1,21379 & & \\
\hline Empatia & $\begin{array}{l}\text { [O horário de operação da MGS é conveniente aos } \\
\text { seus clientes.] }\end{array}$ & 4,9762 & ,89683 & & \\
\hline Negócios & $\begin{array}{l}\text { [Eu certamente voltaria a fazer negócios com a } \\
\text { MGS.] }\end{array}$ & 4,5000 & 1,36596 & \multirow{4}{*}{4,39285714} & \multirow{4}{*}{1,25273903} \\
\hline Negócios & $\begin{array}{l}\text { [Os serviços prestados pela MGS são de alta } \\
\text { qualidade.] }\end{array}$ & 4,3333 & 1,33739 & & \\
\hline Negócios & $\begin{array}{l}\text { [Estou satisfeito com os serviços prestados pela } \\
\text { MGS.] }\end{array}$ & 4,3095 & 1,31572 & & \\
\hline \multirow[t]{2}{*}{ Negócios } & $\begin{array}{l}\text { [As mudanças de processos da MGS implantadas } \\
\text { no último ano melhoraram a qualidade dos } \\
\text { serviços prestados.] }\end{array}$ & 4,4286 & ,96633 & & \\
\hline & Média & 4,5384615 & 1,2374077 & & \\
\hline
\end{tabular}

A tabela 2 demonstra os resultados estratificados pela caracterização dos clientes dentro da administração pública. Após a estratificação, é possível avaliar que nenhum dos grupos, quais sejam: administração direta; autarquia; fundação; empresa pública / sociedade de economia mista / autônomos e outros; se afasta do padrão de normalidade da análise média dos resultados. Todavia, cabe destacar o

\footnotetext{
${ }^{1}$ Os indicadores foram avaliados pelos respondentes na escala: discordo totalmente $=1$; discordo muito = 2; discordo = 3; não concordo, nem discordo $=4$; concordo $=5 ;$ concordo muito $=6$; e concordo totalmente $=7$.
} 
resultado do grupo 'autarquia', com maior nível de qualidade auferido e com menor nível de desvio padrão, e do grupo 'fundação', que tem o pior resultado, por outro lado, o maior nível de desvio padrão.

Tabela 2: Valor médio dos indicadores, estratificando pela caracterização do cliente.

\begin{tabular}{|c|c|c|c|}
\hline Caracterização do Cliente & Média Geral & Desvio Padrão & Observações \\
\hline Todos & 4,5385 & 1,23741 & 42 \\
\hline Administração Direta & 4,5620 & 1,28506 & 18 \\
\hline Autarquia & 4,8195 & 0,94884 & 13 \\
\hline Fundação & 4,0288 & 1,36265 & 8 \\
\hline Empresas Públicas/ Sociedade de Economia Mista / Autônomos e Outros & 4,5385 & 1,06477 & 3 \\
\hline
\end{tabular}

A tabela 3 demonstra os resultados estratificados pelo tempo de atuação dos gestores a frente dos contratos com a MGS. Após a estratificação, tal qual na estratificação anterior, é possível avaliar que nenhum dos grupos se afasta do padrão de normalidade da análise média dos resultados. Nesta análise os grupos são: 5 anos ou mais; de 3 a 4 anos; de 1 a 2 anos; até 1 ano.

Tabela 3: Valor médio dos indicadores, estratificando pelo tempo de atuação do gestor.

\begin{tabular}{|l|l|l|l|}
\hline Caracterização do Cliente & Média Geral & Desvio Padrão & Observações \\
\hline Todos & 4,5385 & 1,23741 & 42 \\
\hline 5 anos ou mais & 4,5909 & 1,17461 & 11 \\
\hline De 3 a 4 anos & 4,5549 &, 96801 & 7 \\
\hline De 1 a 2 anos & 4,3432 & 1,50948 & 13 \\
\hline Até 1 ano & 4,7063 & 1,02358 & 11 \\
\hline
\end{tabular}

A tabela 4 traz os dados da análise de confiabilidade do alfa de Cronbach dentre as dimensões da qualidade avaliadas. $\mathrm{O}$ alfa de Cronbach é o coeficiente de confiabilidade mais amplamente utilizado, que varia de 0 a 1, e tem 0,60 como limite inferior de aceitabilidade (HAIR, 2005). Os resultados, apresentados demonstraram que todas as dimensões alcançaram o nível mínimo de aceitabilidade.

Tabela 4: Confiabilidade dos indicadores de qualidade.

\begin{tabular}{|c|c|c|}
\hline Dimensão & Declaração & $\begin{array}{l}\text { Alfa de } \\
\text { Cronbach }\end{array}$ \\
\hline Tangibilidade & [Os insumos entregues pela MGS são adequados aos serviços prestados.] & \multirow{4}{*}{0,678937} \\
\hline Tangibilidade & [A estrutura tecnológica da MGS (portal, área do cliente) atende suas necessidades.] & \\
\hline Tangibilidade & [Os empregados da MGS utilizam vestimentas adequadas aos serviços prestados.] & \\
\hline Tangibilidade & $\begin{array}{l}\text { [As instalações físicas da administração central da MGS são suficientes para suportar o serviço } \\
\text { prestado.] }\end{array}$ & \\
\hline Confiança & [A MGS cumpre suas obrigações contratuais.] & \multirow{5}{*}{0,914106} \\
\hline Confiança & [Quando você tem algum problema a MGS demonstra interesse em resolvê-lo.] & \\
\hline Confiança & [A MGS é confiável.] & \\
\hline Confiança & [A MGS entrega os serviços no prazo prometido.] & \\
\hline Confiança & [A MGS mantém os registros históricos de maneira adequada.] & \\
\hline Receptividade & [Os empregados da administração da MGS entregam as informações da forma correta.] & \multirow{4}{*}{0,863494} \\
\hline Receptividade & [Os empregados da administração da MGS prestam um pronto atendimento.] & \\
\hline Receptividade & [Os empregados da administração da MGS ficam sempre à disposição para auxiliar os clientes.] & \\
\hline Receptividade & $\begin{array}{l}\text { [Os empregados da administração da MGS nunca estão muito ocupados para responder aos } \\
\text { clientes prontamente.] }\end{array}$ & \\
\hline Segurança & [você pode confiar nos empregados da MGS.] & \multirow{4}{*}{0,810738} \\
\hline Segurança & [Você se sente seguro ao negociar com os empregados da MGS.] & \\
\hline Segurança & [Os empregados da MGS são educados.] & \\
\hline Segurança & [Os empregados tem o suporte adequado da MGS para realizar o seu trabalho.] & \\
\hline Empatia & [A MGS te dá atenção individual.] & \multirow{5}{*}{0,875565} \\
\hline Empatia & [Os empregados da administração da MGS te dão atenção personalizada.] & \\
\hline Empatia & [Os empregados da administração da MGS conhecem suas necessidades.] & \\
\hline Empatia & [A MGS coloca seus interesses como prioridade.] & \\
\hline Empatia & [O horário de operação da MGS é conveniente aos seus clientes.] & \\
\hline
\end{tabular}




\begin{tabular}{|l|l|l|}
\hline Negócios & [Eu certamente voltaria a fazer negócios com a MGS.] & 0,924159 \\
\hline Negócios & [Os serviços prestados pela MGS são de alta qualidade.] \\
\hline Negócios & [Estou satisfeito com os serviços prestados pela MGS.] & $\begin{array}{l}\text { [As mudanças de processos da MGS implantadas no último ano melhoraram a qualidade dos } \\
\text { serviços prestados.] }\end{array}$ \\
\hline
\end{tabular}

\section{CONCLUSÕES}

Este trabalho teve como objetivo principal medir a qualidade dos serviços prestados ao cliente da empresa MGS. Em busca desse propósito, foi utilizado do instrumento SERVPERF proposto por Cronin et al. (1992), cuja aferição se deu através dos resultados obtidos em cada uma das dimensões da qualidade, quais sejam: tangibilidade, confiança, receptividade, segurança, empatia, além do agrupamento das quatro declarações que buscavam medir amplas intenções dos clientes, nessa pesquisa chamado de 'negócios'.

O instrumento SERVPERF utilizado nesse trabalho foi composto por 26 declarações, distribuídas da seguinte forma: As declarações de 1 a 4 foram vinculadas à dimensão 'tangibilidade'; de 5 a 9 à dimensão 'confiança'; de 10 a 13 à dimensão 'receptividade'; de 14 a 17 à dimensão 'segurança'; de 18 a 22 à dimensão 'empatia'; e, por fim, de 23 a 26 à dimensão 'negócios'. Além das perguntas preconizadas no SERVPERF, o questionário contou com cinco perguntas demográficas para análise atual e futura do perfil dos respondentes, as perguntas buscaram levantar: a esfera da administração pública a qual se vincula o cliente; o poder da administração pública ao qual se vincula o cliente; caracterização do cliente dentro da administração pública; o tempo de contratação da MGS pelo cliente; e o tempo de gestão do respondente à frente do cliente.

Os dados foram examinados de maneira quantitativa, através da média aritmética das respostas dos clientes. Foram observadas também as diferenças entre os grupos, levantadas através das perguntas demográficas do questionário. Além disso, foi utilizado do alfa de Cronbach, para analisar a confiabilidade sobre as dimensões da qualidade de serviços.

Diante dos resultados, foi possível verificar que os serviços da MGS apresentam um nível de qualidade aceitável, já que todas as dimensões apresentaram resultados acima da opção 'não concordo, nem discordo', sendo possível inferir que, se não há satisfação plena, os clientes também não estão insatisfeitos com a qualidade dos serviços. Além disso, não há diferenciação expressiva no resultado quando a análise é estratificada por grupos, seja pela caracterização do cliente dentro da administração pública, quanto pelo tempo de gestão do respondente à frente do cliente. Por fim, o alfa de Cronbach alcançado em cada uma das dimensões da qualidade confirmaram que a confiabilidade do questionário, já que os valores ficaram acima do limite inferior de aceitabilidade.

A extensão do questionário, mesmo que consideravelmente menor do que o SERVQUAL, demonstrou-se uma barreira para alcançar um número maior de respondentes, mesmo dentro de uma população relativamente pequena. Todavia, foi confirmado que o instrumento SERVPERF é uma ferramenta adequada para a mensuração da qualidade em serviços. Seja pela validade do instrumento, amplamente confirmada na literatura acadêmica, quanto pela sua confiabilidade atestada nesse trabalho. 
A medição e acompanhamento da qualidade são passos fundamentais para a busca de melhoria contínua, maior assertividade na tomada de decisões e consequentemente o alcance da satisfação por parte dos clientes. Para trabalhos futuros, é sugestão razoável a continuidade dessa pesquisa com a aplicação do questionário para os clientes da MGS nos próximos anos, para que seja possível analisar as mudanças de comportamento, através da comparação da série histórica, auxiliando os gestores a seguir as melhores rotas e corrigir os rumos, quando necessário.

\section{REFERÊNCIAS}

CRONIN, J. J.; TAYLOR, S. A. SERVPERF versUS SERVQUAL: reconciling performance-based and perceptions-minusexpectations measurement of service quality. Journal of Marketing, Birmingham, v.58, p.125-131, 1994.

CRONIN, J. J.; TAYLOR, S. A.. Mensuring Service Quality: a reexamination and extension. Journal of Marketing, Birmingham, v.56, p.55-68, 1992.

FJP. Fundação João Pinheiro. Produto interno bruto de Minas Gerais: relatório anual 2010-2013. Belo Horizonte: FJP, 2015.

GIL, A. C.. Métodos e técnicas de pesquisa social. 5 ed. São Paulo: Atlas, 1999.

HAIR, J. F.; TATHAM, R. L.; ANDERSON, R. E.; BLACK, W. Análise multivariada de dados. 5 ed. Porto Alegre: Bookman, 2005.

IBGE. Instituto Brasileiro de Geografia e Estatística. Pesquisa Mensal de Emprego: estimativas do mês de fevereiro de 2016 (em mil pessoas). Rio de Janeiro: IBGE, 2016.

LEE, J.; BEELER, C.. The Relationships Among Quality, Satisfaction, and Future Intention for First-time and Repeat Visitors in a Festival Setting. Event Management, Clemson, v.10, n.4, p.197-208, 2007.

MAANEN, J, V.. Reclaiming qualitative methods for organizational research: a preface. Administrative Science Quarterly, Ithaca, v.24, n.4, p.520-526, 1979.

MAIA, M. A.; SALAZAR, A. M. B. K.; RAMOS, P. M. G.. A adequação dos modelos SERVQUAL e SERVPERF na medição da qualidade de serviços: o caso RAR Imobiliária. In: CALVO, J. C. A.. Conocimento, innovación y empreendedores: caminho al futuro. La Rioja: Universidad de La Rioja, 2007.

MALHOTRA, N. K.. Pesquisa de marketing: uma orientação aplicada. 4 ed. Porto Alegre: Bookman, 2006.
MIGUEL, P. A. C.; SALOMI, G. G. E.. Uma revisão dos modelos para medição da qualidade em serviços. Revista Produção, São Paulo, v.14, n.1, p.12-30, 2004.

MIGUEL, P. A. C.; SALOMI, G. G. E.; ABACKERLI, A. J.. SERVQUAL X SERVPERF: comparação entre instrumentos para avaliação da qualidade de serviços internos. Gestão \& Produção, São Paulo, v.12, n.2, p.279-293, 2004.

PARASURAMAN, A.; ZEITHAML, V. A.; BERRY, L. L.. A conceptual model of service quality and its implications for future research. Journal of Marketing, Birmingham, v.49, p.41-50, 1985.

PARASURAMAN, A.; ZEITHAML, V. A.; BERRY, L. L.. Refinement and reassessment of the servqual scale. Journal of Retaliling, v.67, n 4, p.420-450, 1991.

PARASURAMAN, A.; ZEITHAML, V. A.; BERRY, L. L.. Servqual: a multiple-item scale for measuring consumer perceptions of service quality. Journal of Retaliling, v.64, n.1, p.12-37, 1988.

SANTOS, F. B.. Determinantes de custo na limpeza predial terceirizada: benchmarking em universidade federais. Dissertação (Mestrado em Controladoria e Contabilidade) Universidade de São Paulo, São Paulo, 2014.

SILVA, L. M. T.; MEDEIROS, C. A. F.; COSTA, B. K.. Qualidade dos serviços turísticos no setor de restaurantes: uma aplicação do modelo SERVPERF. Revista Hospitalidade, São Paulo, v.6, n.2, p.115-139, 2009.

SLACK, N.; CHAMBERS, S.; JOHNSTON, R.. Administração da Produção. 2 ed. São Paulo: Atlas, 2002.

VERGARA, S. C.. Projetos e relatórios de pesquisa em administração. 3 ed. São Paulo: Atlas, 2000.

A CBPC - Companhia Brasileira de Produção Científica (CNPJ: 11.221.422/0001-03) detém os direitos materiais desta publicação. Os direitos referem-se à publicação do trabalho em qualquer parte do mundo, incluindo os direitos às renovações, expansões e disseminações da contribuição, bem como outros direitos subsidiários. Todos os trabalhos publicados eletronicamente poderão posteriormente ser publicados em coletâneas impressas sob coordenação da Sustenere Publishing, da Companhia Brasileira de Produção Científica e seus parceiros autorizados. Os (as) autores (as) preservam os direitos autorais, mas não têm permissão para a publicação da contribuição em outro meio, impresso ou digital, em português ou em tradução. 